\title{
The SPOROCYTELESS gene of Arabidopsis is required for initiation of sporogenesis and encodes a novel nuclear protein
}

\author{
Wei-Cai Yang, ${ }^{1}$ De Ye, ${ }^{1}$ Jian $\mathrm{Xu}$, and Venkatesan Sundaresan ${ }^{2}$ \\ The Institute of Molecular Agrobiology, National University of Singapore, Singapore 117604
}

\begin{abstract}
The formation of haploid spores marks the initiation of the gametophytic phase of the life cycle of all vascular plants ranging from ferns to angiosperms. In angiosperms, this process is initiated by the differentiation of a subset of floral cells into sporocytes, which then undergo meiotic divisions to form microspores and megaspores. Currently, there is little information available regarding the genes and proteins that regulate this key step in plant reproduction. We report here the identification of a mutation, SPOROCYTELESS (SPL), which blocks sporocyte formation in Arabidopsis thaliana. Analysis of the SPL mutation suggests that development of the anther walls and the tapetum and microsporocyte formation are tightly coupled, and that nucellar development may be dependent on megasporocyte formation. Molecular cloning of the SPL gene showed that it encodes a novel nuclear protein related to MADS box transcription factors and that it is expressed during microsporogenesis and megasporogenesis. These data suggest that the SPL gene product is a transcriptional regulator of sporocyte development in Arabidopsis.
\end{abstract}

[Key Words: Arabidopsis mutant; sporogenesis; sporocyte; SPL; nuclear protein]

Received May 12, 1999; revised version accepted July 1, 1999.

The life cycle of plants consists of an alternation between a diploid, sporophytic generation and a haploid, gametophytic generation. The gametophytes of lower plants and nonflowering vascular plants such as ferns are free living organisms that undergo differentiation and development independent of the sporophytes, whereas the gametophytes of flowering plants complete their development within the male and female floral organs of the sporophytes. In flowering plants like Arabidopsis, the transition from the sporophytic phase to the gametophytic phase consists of two sequential processes, sporogenesis and gametogenesis. The latter process mainly involves development of haploid spores into mature gametophytes. Sporogenesis is characterized by the differentiation of hypodermal cells in anthers and in ovule primordia into microsporocytes and megasporocytes, respectively (Maheswari 1950; Misra 1962). The sporocyte, or meiocyte, undergoes meiosis to give rise to the microspores and megaspores. Thus, the differentiation step is marked by the acquisition of a meiotic cell fate by a subset of floral cells. In contrast to the yeasts and fungi, there is relatively little information on the genetic regulation of sporogenesis in the plant kingdom (Dickinson

\footnotetext{
${ }^{1}$ These authors contributed equally to this work.

${ }^{2}$ Corresponding author.

E-MAIL director@ima.org.sg; FAX 65-872-7007.
}

1994), although several sporophytic mutants that affect sporogenesis have been reported (Robinson-Beers et al. 1992; Lang et al. 1994; Elliott et al. 1996; Klucher et al. 1996; Schneitz et al. 1997; Byzova et al. 1999; Sanders et al. 1999). Here we report the identification and molecular characterization of a gene SPOROCYTELESS (SPL) that is essential for sporogenesis in both male and female organs in Arabidopsis plants.

\section{Results}

\section{Isolation of the sporocyteless mutation}

The $s p l$ mutation was identified by its complete male and female sterility (Fig. 1A) in a screen of Ds insertion lines in Arabidopsis thaliana ecotype Landsberg erecta (Sundaresan et al. 1995). The sterile phenotype segregated $3: 1$ as a single recessive mutation. In addition, when 359 progeny of $s p l /+$ plants were germinated on medium containing kanamycin, a third of the resistant progeny (88/269) gave rise to sterile plants, indicating linkage between $s p l$ and the kanamycin selection marker within the single $D s$ element in this line. Consistent with the mutation being caused by the $D s$ insertion, $s p l$ homozygous plants in the presence of $A c$ exhibited sectors of reversion, resulting in wild-type flowers with normal siliques adjacent to mutant flowers with infertile siliques (Fig. 1B). 


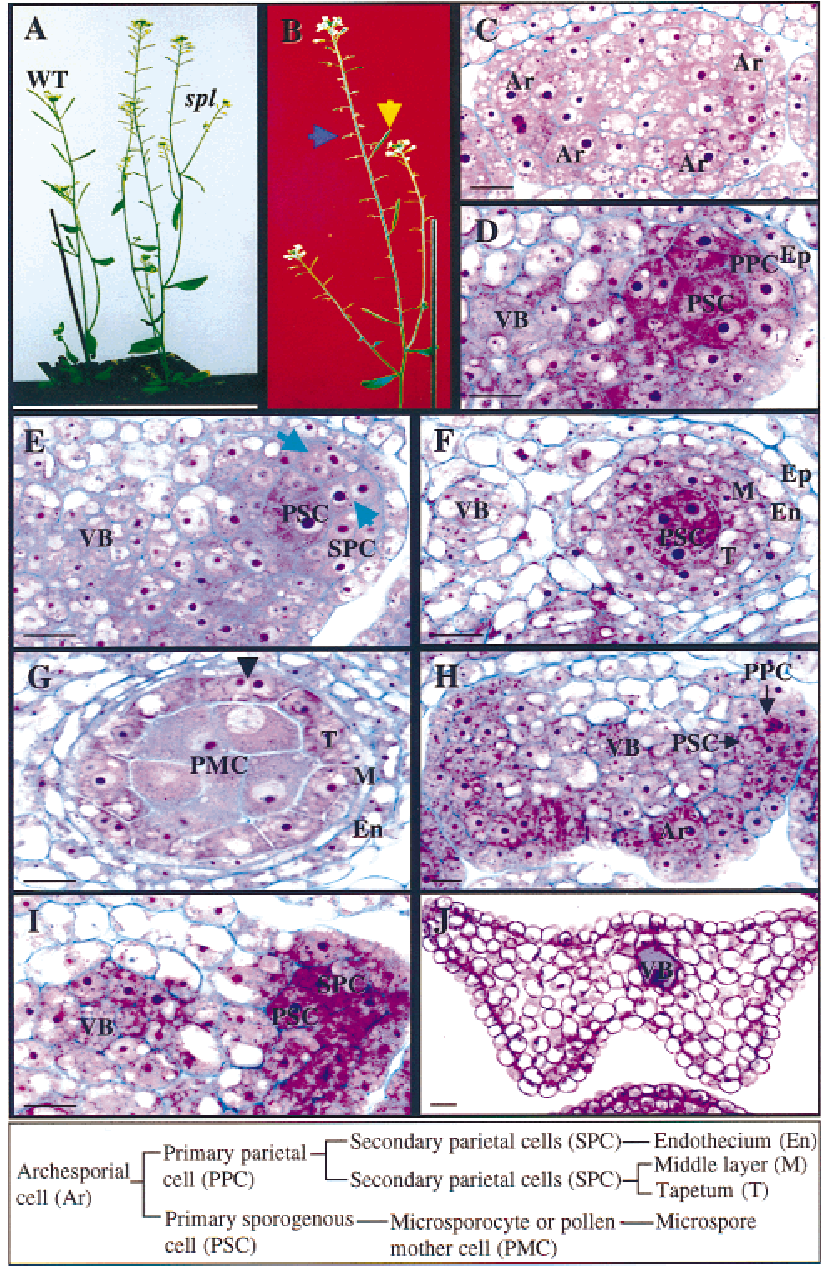

Figure 1. Wild-type and spl mutant phenotype during anther development. The box at bottom shows wild-type cell lineage and nomenclature. $(A)$ Photograph showing wild-type (WT) and the spl mutant plants. (B) Photograph of a mutant plant in which sterile siliques (blue arrow) are reverted to wild type (yellow arrow), demonstrating the excision of $D s$ from the spl gene. $(C-G)$ Micrographs of $5 \mu \mathrm{m}$-thick cross sections of wild-type anthers at different stages. Stages are according to Sanders et al. (1999). (C) Four archesporial cells (Ar) are visible at the four corners of a stage 2 anther. $(D)$ One developing locule at stage 3 showing the PSC and the PPC. The cells close to the vascular bundle (VB) also divide and participate in the formation of the archesporium. (E) Part of an anther at stage 4 showing the SPCs. (Arrows) Cell wall between newly formed SPCs. (F) Part of an anther at stage 5 showing the formation of tapetum $(\mathrm{T})$, the middle layer (M) and endothecium (En). (G) An anther at stage 6 shows one of the four microsporangia. The microsporocyte or $\mathrm{PMC}$ is enlarged just prior to entering meiosis. The tapetum becomes binucleated (arrowhead). (H-J) Micrographs of $5 \mu \mathrm{m}$ thick cross sections from spl mutant anthers. (H) An Ar is visible at the lower right corner and PSCs and PPCs at the upper right corner in stage 2 and 3 anthers. (I) Part of an anther at stage 4 showing development of the SPCs. (J) A cross section of a spl mutant anther at maturity. All cells are vacuolated. (Ep) epidermis. Bar, $10 \mu \mathrm{m}$.

The spl homozygous plants exhibit an overall morphology that is similar to the wild-type plants except that senescence is delayed (Fig. 1A), which is typical for sterile plants (Robinson-Beers et al. 1992). Flowers of the spl plants have normal external morphology and the same number of organs as wild type, except the anthers are white and contain no pollen grains at anthesis during stage 13-14 (Smyth et al. 1990). The carpels look morphologically normal but are infertile when pollinated with wild-type pollen. Cytological studies with wholemount clearing (Herr 1971) and sectioning revealed that sporocyte formation was affected in these plants.

\section{The spl mutation blocks microsporocyte and anther wall formation}

Microsporogenesis in wild-type Arabidopsis follows the pattern typical for dicotyledonous plants (Misra 1962; Bhandari 1984; Sanders et al. 1999). In wild-type flowers, hypodermal cells at the four corners of the anther expand radially and differentiate into archesporial cells at stage 2 of anther development in stage 7 flowers (Fig. 1C; Sanders et al. 1999). Archesporial cells undergo periclinal divisions, giving rise to an inner primary sporogenous cell (PSC) layer and an outer primary parietal cell (PPC) layer at stage 3 anthers (Fig. 1D). The latter subsequently divides periclinally and anticlinally to form two secondary parietal cell (SPC) layers at stage 4 anthers (Fig. 1E). The inner SPCs differentiate into the tapetum, whereas the outer SPCs undergo one more periclinal division, to generate the endothecium and the middle layer at stage 5 anthers (Fig. 1F). At this time, the PSCs differentiate into microsporocytes or pollen mother cells (PMC) and the PMCs become isolated from each other by the deposition of callose on the cell wall at stage 6 anthers, and undergo meiosis to generate the microspores (Owen and Makaroff 1995). Concomitantly, the tapetum is evident and becomes binucleate (Fig. 1G). In spl anthers at stage 2, the hypodermal cells of the anther enlarge and differentiate into archesporial cells normally (Fig. 1H). As in wildtype flowers, the archesporial cells are able to undergo periclinal divisions to form the PPC layer and the PSC layer at stage 3 anthers (Fig. 1H). However, the PSCs in mutant flowers do not form microsporocytes, and instead become vacuolated at stage 4 anthers. The parietal cells are also affected, because the PPCs go through only one division to give rise to two SPC layers that fail to divide further and differentiate (Fig. 1I). There is no endothecium or tapetum formation. At anthesis, mutant anthers are composed of highly vacuolated parenchyma cells (Fig. 1J). We conclude that the $s p 1$ mutation blocks the differentiation of primary sporogenous cells into microsporocytes and anther wall formation.

\section{Archesporial cells fail to differentiate into megasporocytes in spl ovules}

Megasporogenesis and megagametogenesis in Arabidopsis have been extensively described in several reports and reviews (Misra 1962; Reiser and Fisher 1993; Schneitz et 
Yang et al.

al. 1995; Angenent and Colombo 1996; Drews et al. 1998; Gasser et al. 1998; Grossniklaus and Schneitz 1998; Schneitz et al. 1998). The bitegmic and tenuinucellate ovules arise as a finger-like structure on the placenta in the ovaries (carpels). In stage 10-11 flowers, an archesporial cell forms from a single hypodermal cell at the top of the ovule primordium, becoming more prominent than neighboring cells because of its slightly larger size, denser cytoplasm, and more conspicuous nucleus (Fig. 2A). In some flowering plants, the archesporial cell of the ovule undergoes a periclinal division, and subsequently the inner cell differentiates into the megasporocyte. However, in the majority of flowering plants including Arabidopsis, the archesporial cell elongates and polarizes longitudinally, and directly differentiates into the megasporocyte or megaspore mother cell (MMC) with obvious change in cell shape from near rectangular to teardrop (Figs. 2B and 7B, below; Willemse 1981; Grossniklaus and Schneitz 1998). The MMC then undergoes meiosis resulting in the formation of four haploid megaspores (tetrad) and the chalazal megaspore becomes the functional spore, whereas the three spores toward the micropyle undergo programmed cell death (Fig. 2C; Webb and Gunning 1990). Shortly after the archesporial cell becomes visible, the inner and outer integuments initiate from epidermal cells at the base of the nucellus, in stage 11 flowers (Fig. 2B,C). The outer integument overgrows the inner integument and finally both inner and outer integuments envelop the nucellus in which the female gametophyte (embryo sac) develops. In stage 13 flowers, the inner cell layer of the inner integument differentiates into a nutritive endothelium, and the nucellus is reabsorbed.

In an spl mutant flower, the initiation of the ovule primordium is normal, and a single hypodermal cell at the top of the primordium is identifiably larger, as in wild-type flowers (Fig. 2D) but fails to elongate (Fig. $2 \mathrm{E}, \mathrm{F})$. Callose deposition was detected late during meiocyte formation and during meiosis in wild-type ovules as described previously (Rodkiewicz 1970; Webb and Gunning 1990; Schneitz et al. 1995), but could not be detected during spl ovule development (not shown). Thus, it appears that although archesporial cells are specified as in wild type, these presumptive archesporial cells are unable to elongate and differentiate into megasporocytes (Fig. 2E,F,H).

To investigate whether archesporial cells in spl ovules are able to enter a meiotic state irrespective of the morphological aspects, the meiosis-I specific AtDMC1 promoter-GUS reporter fusion (Klimyuk and Jones 1997) was introduced into the spl mutant background by crossing (see Materials and Methods). A total of 55 F2 spl
Figure 2. $s p l$ mutant phenotype during ovule development. $A-C$ are from wild-type carpels; $D-K$ are from $s p l$ mutant carpels. All except $A$ and $I$ are micrographs of ovules cleared with Herr's solution viewed under Nomarski optics. Stages are according to Schneitz et al. (1995). The box at bottom shows wild-type cell lineage and nomenclature. $(A)$ Longitudinal section of an ovule primordium at stage 1 -II. Note the archesporial cell (Ar) at top. $(B)$ An ovule primordium at stage 2-III showing the megasporocyte (MMC) and the initiation of both inner (Ii) and outer (Oi) integuments. Note the large megasporocyte spanning about three nucellar cells $(\mathrm{Nu})$ longitudinally. $(C)$ An ovule at stage $2-\mathrm{V}$ shows the functional megaspore (Fs) and two degenerating megaspores (Ds) at the top of the ovule. Another degenerating megaspore is not visible on this plane because of the T-shaped configuration. Both Ii and Oi have elongated along the axis of the ovule. $(D)$ Ovule primordia from a mutant carpel showing the presence of archesporial cells $(\mathrm{Ar})$. (E) Mutant ovule at a similar stage to $B$. Note that the Ar and the nucellus do not elongate longitudinally. The Ii and Oi primordia were initiated. The dotted vertical line delineates the cell wall between the Ar and nucellar cells. (F) A magnification of the boxed area in $G$ shows the arrested $\mathrm{Nu}$ and Ar. Note the size of the apical nucellar and the archesporial cell. (G) A mutant ovule shows the development of the Ii and Oi and the differentiation of endothelium (En). No embryo sac is formed and the nucellus is arrested (boxed area). (H) Magnification of the boxed area in $J$ shows the transversal division (arrows) of the apical nucellar cell. Note the size of Ar. (I) An oblique section of an ovule at the same stage as $K$ shows the finger-like nucellar structure (Fn) and the integuments. (Arrow) Transversal division of the apical nucellar cell. $(J)$ Mutant ovule from stage 13 flower showing the initiation of the finger-like nucellar structure (boxed area). (K) Mutant ovule from stage 14 flower showing the finger-like structure (Fn). (En) Endothelium; (Fu) funiculus. Bar, $5 \mu \mathrm{m}$.

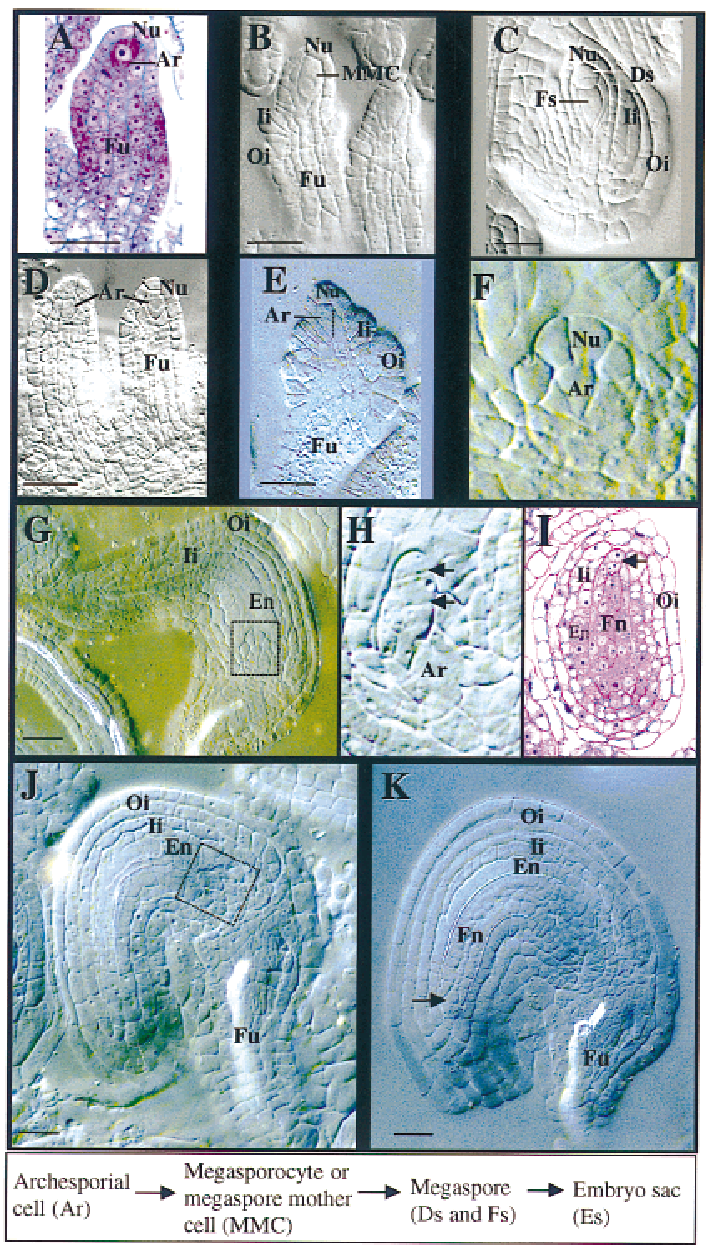


homozygous plants containing the reporter gene were analyzed and none of them showed any GUS activity in either ovules or anthers, whereas strong GUS activity was present in megasporocytes and microsporocytes in wild-type plants carrying the AtDMC1 promoter-GUS fusion (not shown; Klimyuk and Jones 1997). This result confirmed that the archesporial cells of spl mutants do not undergo meiosis. Therefore, we conclude that archesporial cells are formed, but are unable to differentiate into megasporocytes or meiocytes in spl mutants.

Nucellar development but not integument development is affected in spl mutant ovules

Although megasporocytes are not formed in spl ovules (Fig. 2E,F), both inner and outer integuments initiate and differentiate normally as in wild-type flowers (Fig. 2E, G,I,J,K). The endothelium differentiates normally from the inner cell layer of the inner integument (Fig. 2G,I,J,K). Nucellus becomes arrested (Fig. 2E,F) although no morphological abnormality is visible. Shortly after the completion of integument development in stage 13 flowers, the top epidermal cells of the arrested nucellus become elongated and start to divide transversally and mitotically, then the two neighboring nucellar epidermal cells also divide transversally (Fig. $2 \mathrm{H}, \mathrm{I}, \mathrm{K}$ ). As a result, the nucellus grows toward the micropyle to give rise to a finger-like structure during stage 14 (Fig. 2I,K). These observations indicate that the $s p l$ mutation also alters nucellar development, but does not affect integument development.

\section{SPL encodes a nuclear protein with similarity to transcription factors}

Genomic sequences flanking the Ds element were obtained by TAIL PCR (Liu et al. 1995; Grossniklaus et al. 1998) and used as probe to screen an Arabidopsis flower cDNA library (Weigel et al. 1992). A cDNA clone of 1.3 $\mathrm{kb}$ was isolated, which encodes a 314 amino-acid peptide with a predicted pI of 9.10 and molecular mass of $34 \mathrm{kD}$ (Fig. 3A). Database searches revealed no overall homology to known proteins, other than a hypothetical protein corresponding to the same gene from the Columbia ecotype sequenced by the Arabidopsis Genome Initiative, M4I22.140 (PID: g3269294) located on chromosome 4. The SPL protein and M4I22.140 hypothetical protein differ in only one amino acid with a change from threonine into lysine at position 295.

More detailed analysis revealed that a 17 amino acidpredicted helix region of the SPL gene product (amino acids 64-80; helix 1, Fig. 3A,B) is homologous to the first helix of the MADS domain from several MADS box transcription factors (Fig. 3C). Furthermore, secondary structure analysis revealed that there is a basic region between residue 41 and 62, followed by two helix regions, 64-85 and 211-235. At the carboxy terminal there is a putative Myc-type helix-loop-helix dimerization domain signature (Fig. 3A,B). In addition, a monopartite

\section{A}

MATSLFFMST DQNSVGNPND LLRNTRLVVN SSGEIRTETL KSRGRKPGSK TGOOKOKKPT LRGMGVAKLE RQRIEEEKKQ LAAATVGDTS SVASISNNAT RLPVPVDPGV VLQGFPSSLG SNRIYCGGVG SGQVMIDPVI SPWGFVETSS TTHELSSISN PQMFNASSNN RCDTCFKKKR LDGDQNNVVR SNGGGFSKYT MIPPPMNGYD QYLLQSDHHQ RSQGFLYDHR IARAASVSAS STTINPYFNE ATNHTGPMEE FGSYMEGNPR NGSGGVKEYE FFPGKYGERV SVVATTSSLV GDCSPNTIDL SLKL

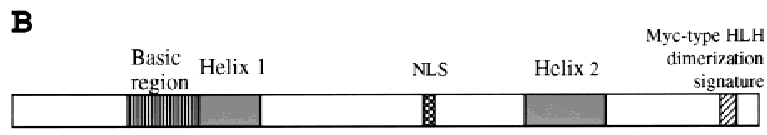

C

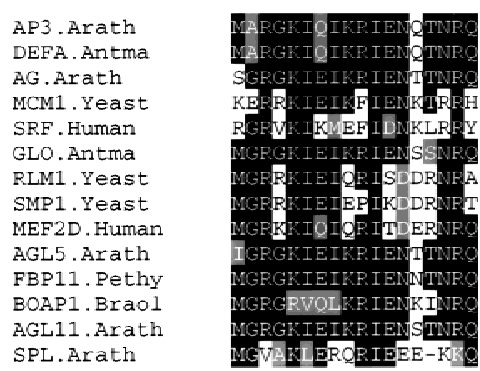

Figure 3. Sequence analysis of SPL polypeptide. (A) Amino acid sequence predicted from the SPL cDNA clone (accession no. AF159255). Underlined sequence from 41 to 62 is a basic region. Sequences in boldface type, 63-85 and 211-235, are putative helix regions. KKKR is a putative nuclear localization signal. Bold underlined sequence, 287-296 represents the putative Myc-type helix-loop-helix dimerization signature. (A) Ds insertion site in spl. (B) Schematic drawing shows SPL protein domain structures starting with the amino-terminal at left. (NLS) Nuclear localization signal. (C) Comparison of SPL protein region between residues 63 and 85 with the helix 1 of the MADS domain from AP3.Arath (accession no. P35632); DEFA.Antma (accession no. P23706); AG.Arath (accession no. P17839); MCM1.Yeast (accession no. P11746); SRF.Human (accession no. P11831); GLO.Antma (accession no. Q03378); RLM1.Yeast (accession no. Q12224); SMP.Yeast (accession no. P38128); MEF2D.Human (accession no. Q14814); AGL5.Arath (accession no. P29385); FBP11.Pethy (accession no. X81852); BOAP1.Braol (accession no. Z37968); AGL11.Arath (accession no. U20182). Residues identical or similar to the SPL sequence are shaded. The dash indicates a gap.

nuclear localization signal (Hicks and Raikhel 1995), KKKR, is present at positions 177-180. Confirmation that SPL is a nuclear protein was obtained from experiments in which a translational fusion between SPL and the GUS reporter gene was introduced into onion epidermal cells and Arabidopsis. The fusion protein was found to be localized to the nucleus (Fig. 4B,C), whereas the control GUS protein is localized throughout the cytoplasm (Fig. 4A). These features suggest that SPL is a nuclear protein and likely functions as a transcription regulator.

DNA gel blot analysis demonstrated that SPL is a single copy gene (Fig. 5A). Comparison of genomic sequences flanking the $D s$ with the cDNA sequence indicated that the $D s$ is inserted at the position 411-412 bp, corresponding to amino acids 110-111 (Fig. 3A). The in- 


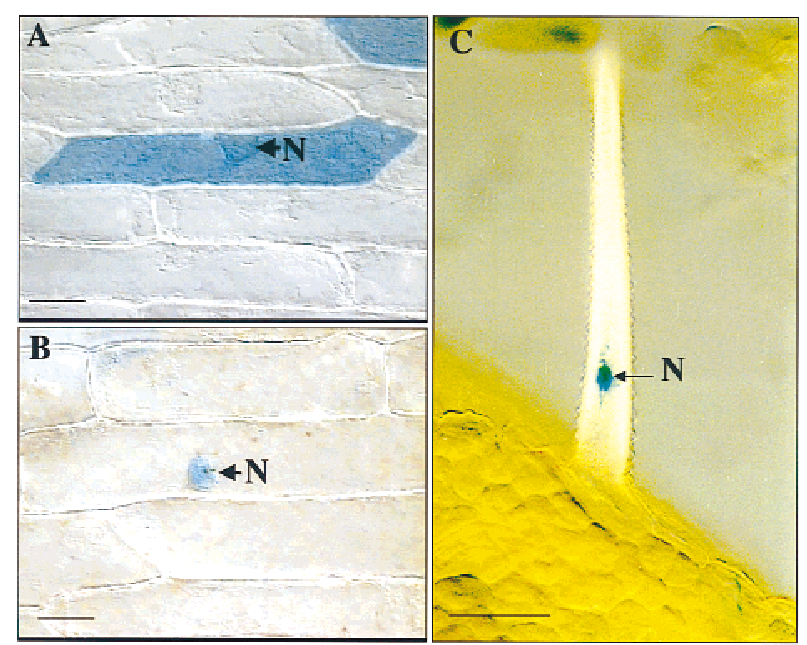

Figure 4. Nuclear localization of SPL-GUS fusion protein. Onion epidermis was bombarded with pBI221 DNA in $A$ and pBI221-SPL-GUS construct in $B$. The pPZP111 construct containing 35 S promoter and SPL-GUS fusion was introduced into Arabidopsis through Agrobacterium-mediated vacuum infiltration in C. Samples were stained for GUS activity. (A) Control GUS protein is distributed throughout the cell. (B) SPL-GUS fusion protein is localized to the nucleus (N). No GUS activity is detected in the cytoplasm. (C) SPL-GUS fusion protein is localized in the nucleus (N) in trichomes of a transgenic Arabidopsis plant. Bar, $10 \mu \mathrm{m}$.

sertion was accompanied by a 4-bp duplication of the host sequence at the insertion site. Ten independent revertant progeny derived from independent revertant siliques from $s p l$ plants carrying $A c$ (Fig. 1B) were analyzed. In each case, it could be verified by PCR amplification that the Ds element had excised (not shown). Sequences flanking the original insertion site from the 10 independent revertants revealed no footprints, indicating perfect excisions of the $D$ s element. The absence of footprints in the revertants suggests that the insertion site may be within a region critical for the function of the SPL protein.

The SPL gene is expressed during microsporogenesis and megasporogenesis

It is unclear from the phenotypic characterization whether the failure of microsporocyte formation is due to the defect in archesporium development itself, or a consequence of the failure of the development of the sporophytic tissues such as the tapetum or the anther walls. To address this question, the expression pattern of the SPL gene was examined by RNA blot and in situ hybridization experiments. A hybridizing band of $1.3 \mathrm{~kb}$ was detected only in flower buds, and not in other organs, such as leaf, silique, and stem (Fig. 5B), indicating that $S P L$ is specifically expressed in flower buds. Furthermore, the SPL gene is weakly expressed in flower buds because $10 \mu \mathrm{g}$ of poly $(\mathrm{A})^{+}$mRNA and long exposure time were required to visualize the hybridization signals. No SPL mRNA was detected in mutant flowers (not shown).
The SPL mRNA was further localized in late sporogenous cells and PMCs in anthers by in situ hybridization. Very weak hybridization signals were first detected in the sporogenous cells in anthers (Fig. 6B) at late stage 3 and stage 4 and stronger signals in microsporocytes were found in anthers at early stage 5 (Fig. 6C,E). No expression was observed in the developing parietal cells that give rise to the anther walls and the tapetum. No signals were detected in anthers younger than stage 3 (Fig. 6A) and in meiocytes at stage 6 (Fig. 6D) as well as in the sense control (Fig. 6F). These data indicate that the $S P L$ gene is expressed specifically in the sporogenous cells and the sporocytes. Therefore, the SPL gene product is most likely to function in the sporogenous cells, rather than in the sporophytic cells like PPCs and SPCs.

It was not possible to obtain reproducible signals for the mRNA localization in developing ovules by in situ hybridization with either digoxigenin-labeled probe or ${ }^{35} \mathrm{~S}$-labeled probe, presumably because of extremely low levels of expression. Therefore, SPL promoter-GUS reporter gene transgenic plants were generated, and the SPL promoter activity in flowers was monitored by staining for GUS activity. In developing ovules, GUS expression was first detected at very low level in the young megasporocytes (Fig. 7B). A slightly higher level was found in older megaspore mother cells as well as adjacent nucellar cells at the micropylar end (Fig. 7C). Frequently, the GUS staining in the MMCs appeared polarized, with staining predominantly at the micropylar end. No GUS expression could be detected in archesporial cells or ovule primordia (Fig. 7A). After meiosis at the early FG1 stage (the stages are as described in Christensen et al. 1997), strong GUS staining was detected in the degenerating nonfunctional megaspores and the surrounding nucellar cells, but not in the functional megaspore at the chalazal end (Fig. 7D). In late FG2 and FG3
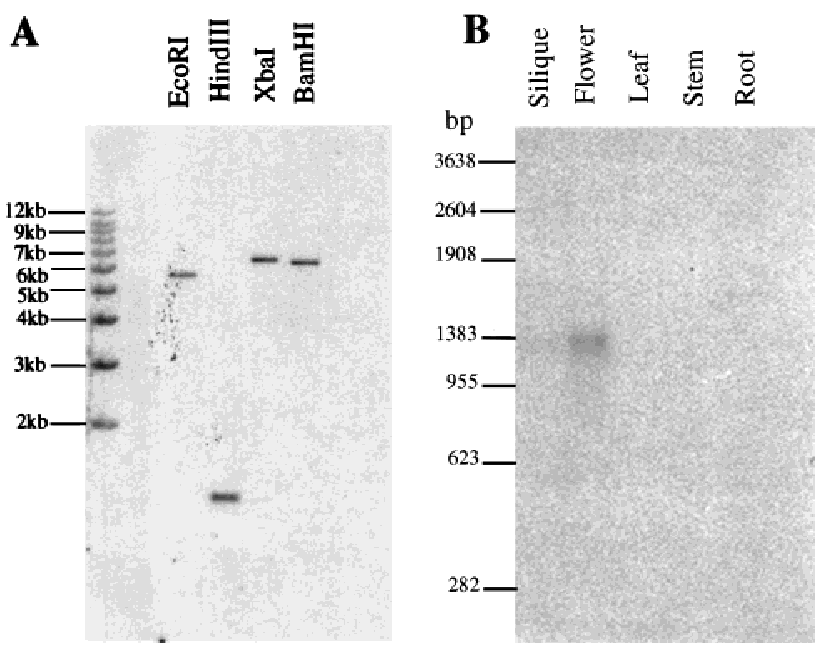

Figure 5. DNA and RNA gel blot analysis of the $S P L$ gene. (A) Autoradiogram of a Southern blot of DNA from Arabidopsis Landsberg erecta, restricted as indicated, and probed with $S P L$ cDNA clone. $(B)$ Northern blot with the SPL cDNA as probe shows $S P L$ expression in flower buds. 


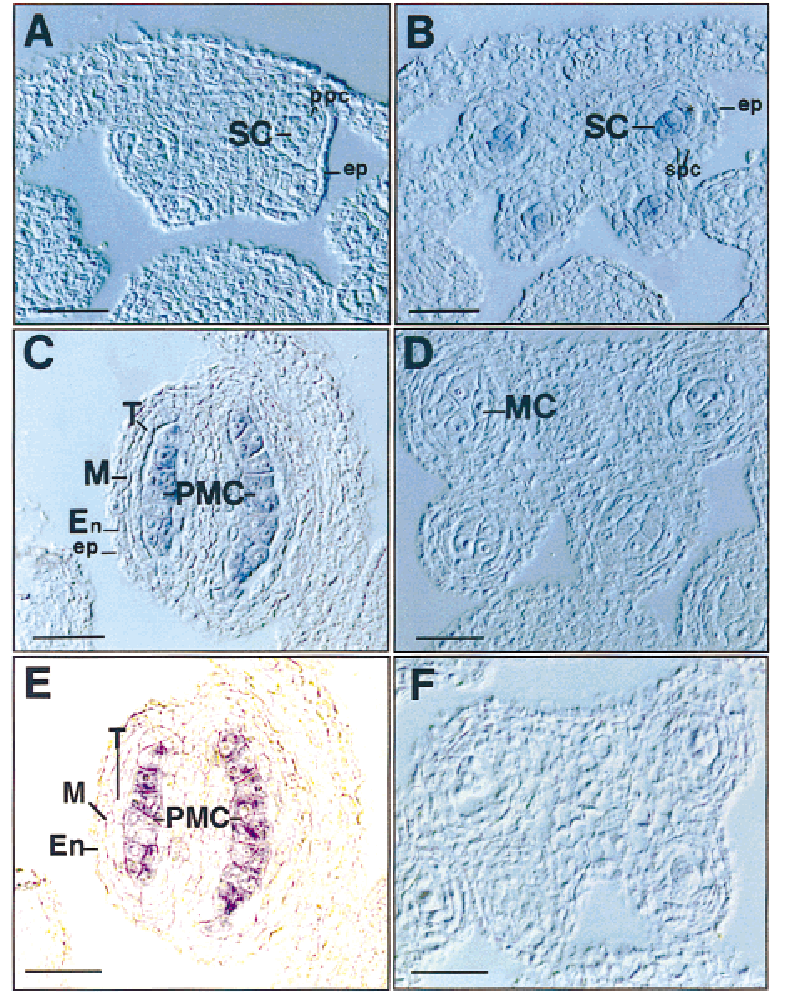

Figure 6. In situ localization of SPL mRNA in anthers. Sections of anthers at different stages were hybridized with DIGlabeled antisense SPL RNA probe and directly photographed with Nomarski or phase-contrast microscopy without counterstaining. Stages are numbered as described by Sanders et al. (1999). (A) Cross section of an early stage 3 anther shows no hybridization signal. $(B)$ Cross section of an anther at early stage 4 shows SPL expression in sporogenous cells (SCs). $\left(^{*}\right)$ newly divided SPCs. $(C)$ Longitudinal section of a stage 5 anther shows $S P L$ expression in microsporocytes or PMCs. (D) Cross section of an anther at meiosis at stage 6 shows no signals in meiotic cells (MCs). (E). Phase-contrast micrograph of the same section as $C$ to highlight the hybridization signals. $(F)$ Cross section of a stage 5 anther hybridized with sense RNA probe as control. (En) Endothecium; (ep) epidermis; (M) middle layer; (ppc) primary parietal cell; $(\mathrm{T})$ tapetum. Bar, $10 \mu \mathrm{m}$.

ovules, only low-level GUS expression in a few nucellar cells at the micropylar end could be detected, and not in the nucellar cells proximal to the chalazal end (Fig. 7E). In later ovules, GUS expression was also found in some residual nucellar cells below the embryo sac at stage FG4 that completely disappeared by stage FG5, at which time all nucellar cells have been reabsorbed (not shown). No GUS activity was detected in other ovule tissues such as the integuments and funiculus. The expression of the $S P L$ promoter-GUS fusion in the anthers was also examined and found to be localized to the sporogenous cells in late stage 3 and 4 anthers, and microsporocytes in anthers at stage 5 (Fig. 7F), consistent with the in situ hybridization data.

\section{Discussion}

The spl mutation causes the disruption of sporocyte for- mation, resulting in the absence of microspores and megaspores, without affecting other aspects of sporophytic development, with the exception of the anther walls and the nucellus. Microsporogenesis and megasporogenesis are highly conserved processes in angiosperms, and the patterns of cell division and differentiation are generally conserved. Because spl mutants show arrest of sporocyte development at a similar stage in both processes, it can be inferred that the $S P L$ gene product plays a general role in sporocyte development that is not restricted to male or female, but the differences in interactions with the surrounding sporophytic cells results in different outcomes in the mutant anthers and ovules.

\section{Function of SPL in microsporogenesis}

Microsporogenesis in Arabidopsis, as in most higher plants, starts with the differentiation of hypodermal



Figure 7. SPL promoter activity monitored by GUS activity. SPL promoter activities visualized by GUS staining at different stages of ovule development and photographed with Nomarski optics. Each purple staining spot represents an individual indigo precipitate viewed through Nomarski optics due to low level of GUS activity and blue staining as in $D$ is due to strong staining that blocks the polarized light. Stages are according to Schneitz et al. (1995) for sporogenesis and Christensen et al. (1997) for gametogenesis respectively. (A) Ovule primordium at stage 1-II shows no GUS staining in archesporial cell (Ar) and nucellus $(\mathrm{Nu})$. (B) Ovule at stage 2-I showing GUS staining in young MMC and distal nucellar cells. $(C)$ Ovule at stage 2-III shows GUS staining in mature MMC and distal nucellus. $(D)$ Ovule at early FG1 stage showing GUS expression in degenerating nonfunctional megaspores (DS) and distal $\mathrm{Nu}$ cells. (E) Ovule at stage FG2 shows weak GUS staining in the distal nucellar cells. Note the absence of staining in the proximal nucellar cells. $(F)$ Micrograph of a stage 5 anther showing GUS expression in PMCs. (En) endothecium; (Es) embryo sac; (f) funiculus; (FS) functional megaspore; (Ii) inner integument; (M) middle layer; (MMC) megaspore mother cell; (Nu) nucellar cell; (Oi) outer integument; (PMC) pollen mother cell; $(\mathrm{T})$ tapetum. Bar, $5 \mu \mathrm{m}$. 
cells that form archesporial cells. The archesporial cells undergo several periclinal divisions to form endothecium, middle layer, and tapetum at the periphery and the PMCs at the center. The coordinated development of the PMCs and the surrounding cell layers might involve cell-to-cell interactions and localized signaling. Our observations suggest that microsporocyte formation and anther wall development may be coupled, because neither microsporocytes nor anther walls are formed in $s p l$ mutant flowers, that is, the development of the SPCs and the PSCs are not cell autonomous. Because the meiocytes and the haploid spores of the tetrads become isolated by callose deposition (Rodkiewicz 1970), it is likely that the signaling occurs early during the formation of microsporocytes. The expression of the SPL gene in the microsporocytes and its absence from the parietal cells suggests that SPL functions within the microsporocytes to regulate expression of a subset of genes required for microsporocyte formation. Therefore, we suggest that the microsporocytes promote, through signal exchange or cell-to-cell interactions, the differentiation and growth of the parietal cell layers, and consequently anther wall development. However, we cannot rule out that the SPL protein itself is transported to the parietal cells to promote their development. We are currently generating antibodies to the SPL protein to address this question more definitively.

SPL is required for megasporocyte formation and plays a role in nucellar development

In $s p l$ mutant ovules, archesporial cell specification is normal, but they fail to differentiate into megasporocytes as demonstrated by the absence of cell expansion, failure to express the meiosis-I specific marker gene At$D M C 1$, and the absence of meiosis. The failure to form megasporocytes does not affect the development of integuments as demonstrated by phenotypic analysis of the spl mutants. However, nucellar development is affected. Initially, the development of the nucellus is normal until stage 11 flowers, but it is then arrested until the completion of integument development in spl mutants at stage 13. It is not clear whether this arrest is due to a direct role for SPL in nucellar development or an indirect consequence of the failure of megasporocyte formation. One possibility is that the development of the nucellus and its programmed cell death may require signals from a functional MMC, megaspore and/or megagametophyte. Intriguingly, in $s p l$ mutants the nucellar cells at the micropyle end start to divide transversally at stage 13 and form a finger-like structure at stage 14 . The timing of the initiation of nucellar cell division coincides with the completion of integument development, and may suggest that there is a signal from the developing integuments that suppresses nucellar cell division during ovule development. However, it is unclear as to why the arrested nucellus in spl mutants develops in a controlled pattern of cell division after the completion of integument formation.

Although the mutant phenotype implied that SPL has a function in ovule development, we could not detect any SPL gene expression in ovules with in situ hybridization with either digoxigenin- or ${ }^{35} \mathrm{~S}$-labeled probe. Therefore, we attempted to monitor SPL gene expression with a SPL promoter-GUS fusion. As described under Results, the SPL promoter is not active in young ovules at the stage when the archesporial cell is visible, but becomes active in the developing megasporocyte and some nucellar cells at the micropylar end during the formation of the megasporocyte. The SPL promoter activity in the megasporocyte is consistent with the mutant phenotype, and the proposed role for the SPL gene product in the differentiation of the archesporial cell into megasporocyte. However, the promoter activity in the nucellar cells as monitored by GUS expression, as well as some other aspects of GUS staining were unexpected, though not inconsistent with the phenotype. The GUS staining in the MMC was frequently asymmetric, with more intensity toward the micropylar end. This asymmetry may reflect the polarization of the cytoplasm, which occurs during the differentiation of the MMC prior to meiosis (Willemse 1981). After meiosis, strong staining in the nonfunctional megaspores, but not in the functional megaspores, was observed. This staining may be the result of expression of SPL in the nonfunctional megaspores prior to programmed cell death. Alternately, it may reflect residual GUS enzyme that is more accessible to the histochemical substrate as the cells begin to degenerate. Interestingly, we detected GUS expression in nucellar cells at the micropylar end during MMC differentiation, and subsequently at the chalazal end after meiosis, suggesting that SPL expression precedes programmed cell death in nucellar cells. Therefore, it is possible that SPL also plays a role in promoting programmed cell death of the nonfunctional megaspores and the nucellus. An important caveat of this experiment is that the $2.7 \mathrm{~kb}$ of upstream DNA used in the SPL promoterGUS fusion may not include all the sequence elements for the correct expression pattern in the ovule (e.g., Taylor 1997), even though the GUS staining in the anthers was consistent with the in situ hybridization results. Therefore, resolution of these questions awaits detailed studies on the localization of the SPL protein with antibodies.

A few other mutations affecting the initiation of microsporogenesis and megasporogenesis have been described in angiosperms. The maize mutation multiple archesporial cells (mac1) alters the specification of archesporial cells in the ovule, resulting in multiple megasporocytes (Sheridan et al. 1996). Because archesporial cell specification is apparently unaffected in spl mutant ovules, it is likely that in ovules the action of MAC1 in maize precedes that of SPL in Arabidopsis. However, the mac1 mutation does not affect archesporial cell or microsporocyte formation in anthers, but instead causes meiotic arrest. This implies that for anther development, the action of MAC1 may be downstream of SPL. In a second maize mutation, ameiotic (am1), both microsporocytes and megasporocytes are formed but they do not undergo meiosis (Golubovskaya et al. 1997), suggesting 
that the AM1 gene product must act at a later stage in maize than SPL in Arabidopsis. More recently, an interesting mutant called sterile apetela (sap) has been described in Arabidopsis in which megasporocytes failed to complete meiosis, and floral organ number and organ identity are also affected (Byzova et al. 1999). Because megasporocyte formation occurs in sap mutants, it is likely that $S A P$ acts downstream of SPL during megasporogenesis.

In conclusion, we have shown that the SPL gene from Arabidopsis is required for sporocyte formation, and consequently for the initiation of the gametophytic phase of the plant life cycle. Integument development in the ovule is independent of megasporogenesis and megagametogenesis, but nucellar development is likely coupled with these processes. In anthers, the development of the sporogenous cells and the parietal cells are not cell autonomous, and the formation of the sporophytic tissues of the anther walls may be dependent on signals from the developing microsporocytes. The sequence and expression pattern of the SPL gene suggest that the gene product most likely functions as a transcriptional regulator essential for microsporogenesis and megasporogenesis.

\section{Materials and methods}

Strains and growth conditions

Seeds of $A$. thaliana ecotype Landsberg erecta (Ler) were directly, or after selection on MS kanamycin plates, grown on soil with $16 \mathrm{hr}$ light $/ 8 \mathrm{hr}$ dark cycle at $22^{\circ} \mathrm{C}$ with $60 \%$ humidity. The generation of $D s$ insertion lines and segregation analysis were carried out according to Sundaresan et al. (1995).

\section{Characterization of spl mutant phenotype}

Flowers from wild-type and $s p l$ mutants were either prefixed with $2.5 \%$ glutaraldehyde or directly cleared with Herr's fluid (85\% lactic acid:chloralhydrate:phenol:clove oil:xylene $=2: 2: 2$ : 2:1 by weight) (Herr 1971) for 1-20 hr and then viewed with a Leica DMRB microscope equipped with differential interference contrast (DIC) optics. For sectioning, flowers were fixed overnight with $3 \%$ glutaraldehyde in $50 \mathrm{~mm}$ phosphate buffer $(\mathrm{pH}$ 7.2) and dehydrated through an ethanol series and embedded into Historesin (Leica) and sectioned with a Leica microtome. Serial sections $(2-5 \mu \mathrm{m}$ thick) were stained with $0.25 \%$ toludine blue $\mathrm{O}(\mathrm{BDH})$ and photographed with the Leica DMRB microscope. To visualize callose deposition, sections and wholemount ovules were stained with $0.01 \%$ decolorized aniline blue (Rodkiewicz 1970; Schneitz et al. 1995). Photos were scanned and composed with Microsoft PowerPoint 4.0 and printed with Tektronix 450 color printer (Tektronix Inc., OR).

\section{Reversion analysis}

A total of 1500 kanamycin-resistant seedlings from F2 families segregating for both $A c$ and the $s p 1$ mutation were transferred to soil. Among them, 13 plants homozygous for the spl mutation and carrying $A c$ were studied further. Somatic excision of the $D s$ from the recessive $s p l$ gene would be able to produce wildtype sectors. Wild-type revertant flowers or siliques appeared on these mutant plants. Seeds were collected from the revertant siliques and selected on MS agar plates containing $50 \mu \mathrm{g} / \mathrm{ml}$ kanamycin and $3.5 \mu \mathrm{M}$ naphthalene acetamide (NAM) (Sigma) for plants having only $D s$, not $A c$ (Sundaresan et al. 1995). Stable revertants were obtained and genomic DNA was extracted from the 10 independent revertants, respectively. Genomic sequences spanning the $D s$ insertion site were obtained by PCR amplification with a upstream primer: 5'-ACAGTCGGAGACACGTCACA-3' and a downstream primer: 5'-GAAGAGGACTCATGAGTAGT-3'. The PCR fragments were gel purified and sequenced.

\section{Molecular cloning of the SPL gene and database searches}

All cloning procedures were performed according to standard methods (Sambrook et al. 1989). Genomic sequences flanking the $D$ s element were obtained with thermal asymmetric interlaced PCR (TAIL PCR) according to Liu et al. (1995) and Grossniklaus et al. (1998). The flanking sequences were sequenced and used as probe to screen a flower cDNA library (Weigel et al. 1992). Sequencing was carried out with an ABI sequencer. Database searching was performed with BLASTN (Altschul et al. 1990) for nucleotide sequences and BLASTP and PSI-BLAST (Altschul et al. 1997) for amino acid sequence. ScanProsite (http://expasy.hcuge.ch) was used for motif search. GOR IV method (Garnier et al. 1996; http://pbil.ibcp.fr) was used for secondary structure prediction and nuclear localization signal was predicted according to Hicks and Raikhel (1995).

\section{Analysis of AtDMC1-GUS expression in spl plants}

Homozygous AtDMC promoter GUS transgenic lines (Klimyuk and Jones 1997) were crossed with spl::Ds/+ plants. $\mathrm{F}_{1}$ plants were selfed and kanamycin-resistant seedlings from $\mathrm{F}_{2}$ seeds were transferred to soil. Spl::Ds/spl::Ds sterile mutants were identified in the $\mathrm{F}_{2}$ plants. Theoretically, $75 \%$ of the mutants should contain the GUS reporter gene. Flower buds from 55 mutants containing the GUS reporter constructs were stained for GUS expression. In contrast to the original line, none of them showed GUS expression in $s p l$ anthers or carpels.

\section{Translational fusion between SPL and GUS proteins}

Two primers, SPL-XbaI-S (5'-CTAGTCTAGTCTAGAAGATCATCA-3') and SPL-BamHI-T (5'-CGGATCCAAGCTTCAAGGACAAATCAATGGT-3'), with introduced enzyme sites immediately upstream of the start codon, and the stop codon respectively, were used to amplify the SPL coding sequence. The PCR fragments were subcloned into pGEM-T vector and sequenced. Then the XbaI-BamHI fragment was subcloned between the $35 \mathrm{~S}$ promoter and the $5^{\prime}$ end of the GUS gene into pBI221 vector (Clontech), giving rise to clone pBI221-SPL-GUS. The SPL-GUS in-frame fusion was confirmed by DNA sequencing. The EcoRI-PstI fragment containing the $35 \mathrm{~S}$ promoter, and SPL-GUS fusion was introduced into pPZP111 (Hajdukiewicz et al. 1994) for plant transformation. The pBI221-SPL-GUS plasmid DNA was then introduced into onion epidermal cells by the Biolistic PDS-1000/He particle delivery system (BioRad). The bombarded onion samples were kept overnight at room temperature and stained for GUS expression as described previously (Sundaresan et al. 1995). Photographs were taken with a Leica DMRB microscope. For plant transformation, the construct was first introduced in Agrobacterium tumefaciens and then introduced into $A$. thaliana ecotype Landsberg erecta by vacuum infiltration. The seeds were selected on kanamycin MS agar plates for transgenic plants. Flower buds from trans- 
Yang et al.

genic plants were analyzed for $S P L$ promoter activity by staining for GUS activity before clearing.

\section{Northern and Southern analysis}

Flower, silique, leaf, and stem tissues were collected from 3-week-old Arabidopsis plants grown on soil. Root tissue was collected from Arabidopsis grown in MS liquid medium with gentle shaking for 3 weeks at $22^{\circ} \mathrm{C}$. Isolation of mRNA was performed with Qiagen RNeasy and Oligotex kits according to the manufacturer's instructions. Poly $(\mathrm{A})^{+}$RNAs $(10 \mu \mathrm{g})$ from each tissue were fractionated on $1 \%$ agarose gel containing formaldehyde. Genomic DNA was extracted according to Liu et al. (1995), restricted and fractionated on $0.9 \%$ agarose gel. The cDNA clone was used as a probe for RNA and DNA blots. The $1.8-\mathrm{kb} E c o R \mathrm{I}$ fragment of the $5^{\prime}-D$ s sequence was used as probe to check Ds copy number (Sundaresan et al. 1995). Northern and Southern blot hybridization were carried out, respectively, according to Sambrook et al. (1989).

\section{In situ hybridization}

Flower buds were fixed with FAA and dehydrated through conventional ethanol series and embedded in paraplast (Leica). Sections $(7-10 \mu \mathrm{m}$ thick)were made with a Leica microtome and deparaffinized with xylene. For antisense probe, the plasmid containing the SPL cDNA clone was linearized with BamHI and in vitro transcribed with T7 RNA polymerase in the presence of DIG-rUTP. To obtain sense probe, the plasmid was linearized with $K p n I$ and in vitro transcribed with T3 RNA polymerase. For SPL mRNA localization in ovules, ${ }^{35}$ S-labeled probe was also used. In situ hybridization was done essentially according to Cox and Goldberg (1988), and post-hybridization wash was performed by incubation twice with $0.2 \times \mathrm{SSC}$ at $55^{\circ} \mathrm{C}$. Immunodection with anti-DIG antibody conjugated with alkaline phosphatase was done according to protocol provided by Boehringer Mannheim.

\section{SPL promoter expression analysis}

A 2.7-kb fragment upstream of the ATG start codon of the predicted SPL gene product was obtained by PCR amplification with two nested primers for the SPL gene: $5^{\prime}$-GGGTCTAGACCATGGTGATGATGATCTTCTTCTCGGACC-3' and 5'-CAGTGTCTCTGTCCGGATCTCGCCGGAGCTAATGAC-3', in combination with the Universal GenomeWalker kit (Clontech) according to the manufacturer's instructions. The PCR fragment was cloned in front of the GUS reporter gene, and then subcloned into pPZP111 (Hajdukiewicz et al. 1994). Plant transformation was carried out as described as above.

\section{Acknowledgments}

We thank Drs. Ueli Grossniklaus and Megan Griffith for critical comments on the manuscript, and Drs. Jonathan Jones and Victor Klimyuk for providing us with the AtDMC promoter GUS reporter transgenic lines. This work was supported by research grants from the National Science and Technology Board of Singapore.

The publication costs of this article were defrayed in part by payment of page charges. This article must therefore be hereby marked 'advertisement' in accordance with 18 USC section 1734 solely to indicate this fact.

\section{Note added in proof}

While this manuscript was under review, the sequence of an
Arabidopsis gene called NOZZLE was made available in GenBank (accession no. AF146794.1) by U. Schiefthaler, S. Balasubramanian, D. Chevalier, P. Sieber, and K. Schneitz (unpubl.). That sequence and the sequence of SPOROCYTELESS are identical.

\section{References}

Altschul, S.F., W. Gish, W. Miller, E.W. Myers, and D.J. Lipmann. 1990. Basic local alignment search tool. J. Mol. Biol. 215: 403-410.

Altschul, S.F., T.L. Madden, A.A. Schaffer, J. Zhang, W. Miller, and D.J. Lipmann. 1997. Gapped BLAST and PSI-BLAST: A new generation of protein database search programs. Nucleic Acids Res. 25: 3389-3402.

Angenent, G.C. and L. Colombo. 1996. Molecular control of ovule development. Trends Plant Sci. 1: 228-232.

Bhandari, N.N. 1984. The Microsporangium. In Embryology of the Angiosperms (ed. B.M. Johri), pp. 53-121. Springer-Verlag, Berlin, Germany.

Byzova, M.V., J. Franken, M.G.M. Aarts, J. de Almeida-Engler, G. Engler, C. Mariani, M.M. Van Lookeren Campagne, and G.C. Angenent. 1999. Arabidopsis STERILE APETALA, a multifunctional gene regulating inflorescence, flower, and ovule development. Genes \& Dev. 13: 1002-1014.

Christensen, C.A., E.J. King, J.R. Jordan, and G.N. Drews. 1997. Megagametogenesis in Arabidopsis wild type and the Gf mutant. Sex Plant Reprod. 10: 49-64.

Cox, K.H. and R.B. Goldberg. 1988. Analysis of plant gene expression. In Plant molecular biology: A practical approach (ed. C.H. Shaw), pp. 1-34. IRL Press, Oxford, UK.

Dickinson, H.G. 1994. The regulation of alternation of generation in flowering plants. Biol. Rev. 69: 419-442.

Drews, G.N., D. Lee, and C.A. Christensen. 1998. Genetic analysis of female gametophyte development and function. Plant Cell 10: 5-17.

Elliott, R.C., A.S. Betzner, E. Huttner, M.P. Oakes, W.Q.J. Tucker, D. Gerentes, P. Perez, and D.R. Smyth. 1996. AINTEGUMENTA, an APETALA2-like gene of Arabidopsis with pleiotropic roles in ovule development and floral organ growth. Plant Cell 8: 155-168.

Garnier, J., J.-F. Gibrat, and B. Robson. 1996. GOR secondary structure prediction method version IV. Methods Enzymol. 266: 540-553.

Gasser, C.S., J. Broadhvest, and B.A. Hauser. 1998. Genetic analysis of ovule development. Annu. Rev. Plant Mol. Biol. 49: $1-24$.

Golubovskaya, I., N. Avalkina, and W.F. Sheridan. 1997. New insights into the role of the maize ameiotic1 locus. Genetics 147: 1339-1350.

Grossniklaus, U. and K. Schneitz. 1998. The molecular and genetic basis of ovule and megagametophyte development. Semin. Cell Dev. Biol. 9: 227-238.

Grossniklaus, U., J.-P. Vielle-Calzada, M.A. Hoeppner, and W.B. Gagliano. 1998. Maternal control of embryogenesis by MEDEA, a Polycomb group gene in Arabidopsis. Science 280: $446-450$.

Hajdukiewicz, P., Z. Svab, and P. Maliga. 1994. The pPZP family of Agrobacterium binary vectors. Plant Mol. Biol. 25: 989-994.

Herr, J.M., Jr. 1971. A new clearing-squash technique for the study of ovule development in angiosperms. Am. J. Bot. 58: $785-790$.

Hicks, G.R. and N.V. Raikhel. 1995. Protein import into the nucleus: An integrated view. Annu. Rev. Cell. Dev. Biol. 
11: $155-188$.

Klimyuk, V.I. and J.D.G. Jones. 1997. AtDMC1, the Arabidopsis homolog of the yeast DMC1 gene: Characterization, transposon-induced allelic variation and meiosis-associated expression. Plant J. 11: 1-14.

Klucher, K.M., H. Chow, L. Reiser, and R.L. Fischer. 1996. The AINTEGUMENTA gene of Arabidopsis required for ovule and female gametophyte development is related to the homeotic gene APETALA2. Plant Cell 8: 137-153.

Lang, J.D., S. Ray, and A. Ray. 1994. sin1, a mutation affecting female fertility in Arabidopsis, interacts with mod1, its recessive modifier. Genetics 173: 1101-1110.

Liu, J.-G., N. Mitsukawa, T. Oosumi, and R.F. Whittier. 1995. Efficient isolation and mapping of Arabidopsis thaliana TDNA insert junctions by thermal asymmetric interlaced PCR. Plant J. 8: 457-463.

Maheswari, P. 1950. An introduction to the embryology of angiosperms. McGraw-Hill, New York, NY.

Misra, R.C. 1962. Contribution to the embryology of Arabdopsis thalianum (Gay and Monn.). Agra. Univ. J. Res. Sci. 11: 191-199.

Owen, H.A. and C.A. Makaroff. 1995. Ultrastructure of microsporogenesis and microgametogenesis in Arabidopsis thaliana (L.) Heynh. Ecotype Wassilewskija (Brassicaceae). Protoplasma 185: 7-21.

Reiser, L. and R. Fisher. 1993. The ovule and the embryo sac. Plant Cell 5: 1291-1301.

Reiser, L., Z. Modrusan, L. Margossian, A. Samach, N. Ohad, G.W. Haughn, and R. Fisher. 1995. The BEL1 gene encodes a homeodomain protein involved in pattern formation in the Arabidopsis ovule primordium. Cell 83: 735-742.

Robinson-Beers, K., R.E. Pruitt, and G.S. Gasser. 1992. Ovule development in wild-type Arabidopsis and two female-sterile mutants. Plant Cell 4: 1237-1249.

Rodkiewicz, B. 1970. Callose in cell walls during megasporogenesis in angiosperms. Planta 93: 39-47.

Sambrook, J., E.F. Fritsch, and T. Maniatis. 1989. Molecular Cloning: A laboratory manual. Cold Spring Harbor Laboratory Press, Cold Spring Harbor, NY.

Sanders, P.M., A.Q. Bui, K. Weterings, K.N. McIntire, Y-C. Hsu, P.Y. Lee, M.T. Truong, T.P. Beals, and R.B. Goldberg. 1999. Anther developmental defects in Arabidopsis thaliana male sterile mutants. Sex Plant Reprod. 11: 297-322.

Schneitz, K., M. Hulskamp, and R.E. Pruitt. 1995. Wild-type ovule development in Arabidopsis thaliana: A light microscope study of cleared whole-mount tissue. Plant J. 7: 731749.

Schneitz, K., M. Hulskamp, S.D. Kopczak, and R.E. Pruitt. 1997. Dissection of sexual organ ontogenesis: A genetic analysis of ovule development in Arabidopsis thaliana. Development 124: 1367-1376.

Schneitz, K., S. Balasubramanian, and U. Schiefthaler. 1998. Organogenesis in plants: The molecular and genetic control of ovule development. Trends Plant Sci. 3: 468-472.

Sheridan, W.F., N.A. Avalkina, I.I. Shamrov, T.B. Batygina, and I.N. Golubovskaya. 1996. The mac1 gene: Controlling the commitment to the meiotic pathway in maize. Genetics 142: 1009-1020.

Smyth, D.R., J.H. Bowman, and E.M. Meyerowitz. 1990. Early flower development in Arabidopsis. Plant Cell 2: 755-767.

Sundaresan, V., P. Springer, T. Volpe, S. Haward, J. Jones, C. Dean, H. Ma, and R. Martiensen. 1995. Patterns of gene action in plant development revealed by enhancer trap and gene trap transposable elements. Genes \& Dev. 9: $1797-1810$.

Taylor, C.B. 1997. Promoter fusion analysis: An insufficient measure of gene expression. Plant Cell 9: 273-275.

Webb, M.C. and B.E.S. Gunning. 1990. Embryo sac development in Arabidopsis thaliana. I. Megasporogenesis, including the microtubular cytoskeleton. Sex Plant Reprod. 3: 244-256.

Wiegel, D., J. Alvarez, D.R. Smyth, M.F. Yanofsky, and E.M. Meyerowitz. 1992. LEAFY controls floral meristem identity in Arabidopsis. Cell 69: 843-859.

Willemse, M.T.M. 1981. Polarity during megasporogenesis and megagametogenesis. Phytomorphology 31: 124-134. 


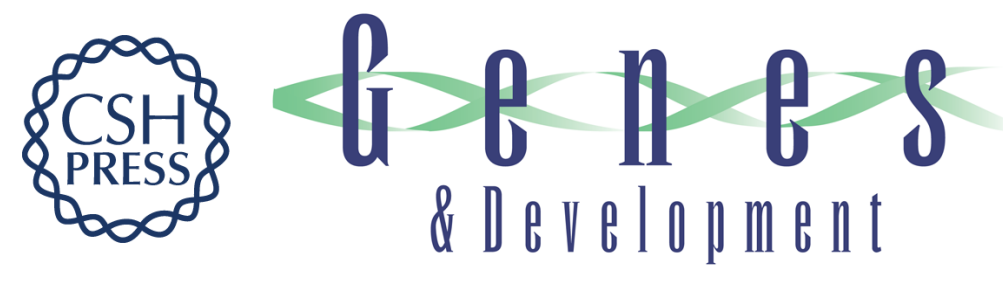

\section{The SPOROCYTELESS gene of Arabidopsis is required for initiation of sporogenesis and encodes a novel nuclear protein}

Wei-Cai Yang, De Ye, Jian Xu, et al.

Genes Dev. 1999, 13:

References This article cites 35 articles, 13 of which can be accessed free at:

http://genesdev.cshlp.org/content/13/16/2108.full.html\#ref-list-1

License

Email Alerting

Receive free email alerts when new articles cite this article - sign up in the box at the top

Service

right corner of the article or click here.



